\title{
UNA ÉLITE RURAL. LOS GRANDES GANADEROS ANDALUCES, SIGLOS XIV-XX
}

por

\author{
ANTONIO LUIS LÓPEZ MARTÍNEZ \\ Universidad de Sevilla
}

RESUMEN: En las grandes explotaciones agrarias de la Baja Andalucía la ganadería jugaba un papel tan importante como los cultivos agricolas. En este tipo de explotaciones la ganadería estaba estrechamente vinculada a la agricultura a la que suministraba trabajo, abonos y dinero en metálico, al tiempo que los ganados se beneficiaban de los barbechos y de los residuos de las cosechas. Dada esta vinculación las figuras del gran agricultor y gran ganadero se fundian en una misma persona que era la del gran labrador que dirigía la explotación agraria. Este gran labrador aprovechaba su importancia económica y social para imponer su poder en los concejos municipales, a fin de inclinar en su propio beneficio la explotación de los espacios rurales colectivos en los que mantenía su ganado durante buena parte del año.

PAlabras Clave: Andalucía. Ganaderia. Élites Rurales. Explotaciones Agrarias. Latifundismo.

ABSTRACT: In the largest estates of Lower Andalusia, livestock farming played a role as important as arable agriculture. In these kinds of estates, livestock farming was closely bound to agriculture, supplying the latter with employment, fertiliser, and cash. At the same time, cattle farming made use of fallow land and of the remnants of the harvests. Due to this link, the figures of the great cattle-owner and the great agriculturalist were blended together into that of the big farmer in charge of his estates. Such a farmer profited from his economic and social status, imposing bis authority on the town councils, so as to incline to bis own benefit the exploitation of collective rural spaces in which livestock were fed during most of the year.

KEY WORDS: Andalusia. Livestock Farming. Rural Élite. Farms. Large Rural State. 
«...nada más alejado de la realidad histórica que la imagen de las campiñas andaluzas sin ganado».1

\section{INTRODUCCIÓN}

Los ingenieros agrónomos encargados de elaborar las memorias que acompañaron a los censos ganaderos realizados entre finales del siglo XIX y primer tercio del siglo XX coincidían en señalar la importancia histórica que la ganadería había tenido en Andalucía occidental. Destacando que, para algunas provincias como Sevilla y Cádiz, la ganadería constituía una de sus principales fuentes de riqueza. Sin embargo, esta importancia de la ganadería andaluza contrasta con la escasez de estudios sobre la historia ganadera de la región. Posiblemente, esto se deba a la escasa penetración que en Andalucía tuvo la Mesta, casi exclusiva protagonista de la historiografía sobre la ganadería española en el Antiguo Régimen, así como la escasa fiabilidad de algunos de los principales censos ganaderos oficiales del período contemporáneo, cuestionados tanto por las ocultaciones como por la falta de homogeneidad de sus resultados.

Han sido los historiadores medievalistas los que más atención han prestado al estudio de la ganadería andaluza. Argente Castillo para los reinos de Jaén y Córdoba $^{2}$ y Carmona Ruiz para el reino de Sevilla ${ }^{3}$, analizan las instituciones y ordenanzas que favorecieron la expansión ganadera en la región, y también han elaborado a partir de los padrones fiscales los primeros censos ganaderos de la misma. Esto contrasta con la ausencia de estudios sobre la ganadería en la Edad Moderna, que se limitan a ofrecer algunos datos aislados en monografías locales y ningún análisis de conjunto. Para la época contemporánea, sólo en los estudios generales sobre la ganadería española se hace referencia a la ganadería de Andalucía occidental $^{4}$, faltando estudios monográficos dedicados a la ganadería de la región.

La historiografía tradicional ha venido sosteniendo la existencia de una pugna tradicional entre labradores y ganaderos que se habrían enfrentado durante siglos por el control de las tierras. Los ganaderos serían partidarios de los campos abiertos y el mantenimiento de los derechos comunes, baldíos y derrota de mieses, que les daría libre acceso a los pastos y rastrojeras que necesitan sus ganados. Por su parte, los labradores aparecerían como partidarios del aprovechamiento exclusivo de sus tierras mediante los cerramientos, así como del reparto de los baldíos para su puesta en cultivo.

1 Bernal, Antonio Miguel: Economía e historia de los latifundios, Madrid, 1988.

2 La ganadería medieval andaluza. Siglos XIII-XV Reinos de Jaén y Córdoba), Jaén, 1991.

3 La ganadería en el reino de Sevilla durante la Baja Edad Media, Sevilla, 1998.

4 GARCía SANZ, Angel: «La ganadería española entre 1759 y 1865: los efectos de la reforma agraria liberal» en Agricultura y Sociedad (Madrid) 72 (1994), pp. 81-119 y G.E.H.R.: «Contribución al análisis histórico de la ganadería española» en Agricultura y Sociedad (Madrid) 8 (1978), pp. 129 182 y 10 (1979), pp. 105-169. 
Lo que pretendo analizar en este artículo es que este secular enfrentamiento no tuvo lugar en Andalucía occidental, ya que dada la fuerte integración entre agricultura y ganadería en las grandes explotaciones agrarias, los intereses de los grandes ganaderos y labradores no eran contrapuestos, sino que, por el contrario, ambas figuras se unían en una misma persona, el gran labrador que llevaba en explotación una gran superficie cultivada, ya sea propia o en arrendamiento, y que al mismo tiempo era propietario de una gran cabaña ganadera que servía para las labores de la explotación agrícola o que le proporcionaba importantes ingresos mediante su comercialización ${ }^{5}$.

\section{IMPORTANCIA DE LA GANADERÍA EN ANDALUCÍA OCCIDENTAL}

El fuerte cuestionamiento a que se han visto sometidos los censos ganaderos antes mencionados no los invalida totalmente. Posiblemente, no permitan conocer con exactitud la evolución del número de cabezas de la región, pero sí establecer la tendencia experimentada por la cabaña ganadera regional, así como su estructura.

Los primeros datos disponibles sobre la composición de la cabaña ganadera en la región datan de finales del siglo XV y corresponden a los "padrones de cuantía» que fueron elaborados en la «Tierra de Sevilla» con un carácter fiscal. A partir de estos padrones se abre un largo paréntesis, sin apenas datos ganaderos, que sólo se cerrará a mediados del siglo XVIII gracias a la abundante información proporcionada por el Catastro de Ensenada y documentación con él relacionada, que ha sido recogida por el Instituto Nacional de Estadística ${ }^{6}$. Tras otro paréntesis de un siglo ${ }^{7}$, en 1865 se inicia la serie de censos generales contemporáneos de la ganadería española ${ }^{8}$. Durante el siglo $\mathrm{XX}^{9}$ estos censos ganaderos serán relativamente frecuentes.

En el Cuadro 1 hemos recogido el resumen de los datos relativos a la composición de la cabaña ganadera de Andalucía Occidental contenidos en los citados censos ganaderos.

5 López MARTínez, Antonio Luis: «La cría del ganado de lidia y la gran explotación agraria en Andalucía (s. XVIII-XX)» en Revista Española de Estudios Agrosociales y Pesqueros (Madrid) 184 (1998), pp. 137-158.

6 I.N.E.: Censo ganadero de la Corona de Castilla, año de 1752, Madrid, 1996.

7 El Censo de Frutos y Manufacturas, cuyos datos se refieren a 1799, no sirve para Andalucía, ya que sólo informa de las crías nacidas en cada año y no del número total de cabezas de ganado.

8 JUNTA GENERAL DE ESTADístiCa: Censo de la ganadería de España, según recuento verificado el 24-IX-1865, Madrid, 1865.

9 Ministerio de Agricultura. Dirección General de Agricultura.- Tres estudios económicos. Apéndice al Anuario estadístico de las producciones agrícolas 1933, Madrid, 1934. 


\section{CUADRO 1. COMPOSICIÓN DE LA CABAÑa GANADERA EN ANDALUCÍA OCCIDENTAL. SIGLOS XV-XX ${ }^{10}$}

\begin{tabular}{|l|c|c|c|c|c|c|c|c|}
\hline \multicolumn{1}{|c|}{ Años } & Vacuno & Caballar & Mular & Asnal & Ovino & Caprino & Porcino & U.G. \\
\hline $1500^{11}$ & 46.289 & 4.628 & 1.239 & 7.366 & 70.253 & 26.798 & 46.591 & 70.540 \\
\hline 1752 & 300.659 & 63.577 & 14.039 & 97.795 & 1.282 .661 & 608.415 & 322.707 & 656.048 \\
\hline 1865 & 278.926 & 118.521 & 76.476 & 144.957 & 1.259 .069 & 650.241 & 551.626 & 853.955 \\
\hline 1933 & 282.217 & 81.509 & 162.105 & 97.393 & 1.105 .635 & 518.195 & 865.246 & 901.549 \\
\hline
\end{tabular}

Datos en número de cabezas, U.G. son unidades ganaderas según el criterio F.A.O.

Fuentes: CARMONA RUIZ, M.A.: «Volumen y distribución de la cabaña ganadera en el Reino de SeviLla. Finales del XV - Principios del XVI» en Historia. Instituciones. Documentos (Sevilla), 28 (2001), pp. 31-89 y SANCHO SOPRANIS, H.: Historia social de Jerez de la Frontera al fin de la Edad Media. La vida material, I, Jerez. de la Frontera, 1964 para 1500, el resto, los censos ganaderos anteriormente citados.

A lo largo de este período se produjo un cambio estructural en la composición de la cabaña ganadera de la región, tal como se aprecia en el cuadro 1. El ganado vacuno siguió ostentando la primacía en la región en cuanto a unidades ganaderas, mientras que el ganado ovino era el que registraba mayor número de cabezas. Sin embargo, el rasgo más destacado fue el fuerte crecimiento experimentado por los ganados mular y porcino. El espectacular crecimiento del ganado mular es como consecuencia de la progresiva sustitución del buey por la mula como ganado de labor, especialmente en las comarcas olivareras, si bien esta sustitución nunca llegó a consumarse para toda la región, en buena parte de la cual, especialmente en las zonas bajas y arcillosas, el buey siguió jugando una papel importante como fuerza de tracción. El incremento del porcino está relacionado con el consumo de carne ${ }^{12}$ debido al aumento de la población y a una relativa mejora en el nivel de vida ${ }^{13}$. En el resto de las especies las variaciones en el largo plazo fueron escasas, el ganado caballar conoció un ligero incremento, el asnal se estancó, mientras que vacuno, ovino y caprino conocieron una disminución.

10 Este cuadro no pretende reflejar la evolución del número de las cabezas de ganado existentes en la región, sino la estructura de la cabaña ganadera para destacar la importancia que en dicha cabaña tenían ciertas especies ganaderas.

11 Corresponde sólo a los padrones hechos en las localidades de la Tierra de Sevilla y Jerez de la Frontera entre finales del siglo XV y comienzos del XVI. No abarca, por tanto la totalidad del territorio analizado en este artículo. Su inclusión obedece únicamente a nuestra intención de resaltar la importancia de las especies ganaderas más destacadas.

12 El $41 \%$ de la carne consumida en 1865 procede del ganado porcino (GARCía SANZ: op. cit, p. 101)

13 G.E.H.R.: op. cit., $\mathrm{n}^{\circ} 10$, p. 122-123.

Hispania, LXV/3, núm. 221 (2005) 1023-1042 


\section{LAS GRANDES GANADERÍAS ANDALUZAS}

Al igual que en el caso de la tierra, también en la ganadería de Andalucía Occidental existía una fuerte concentración de la propiedad. La mayoría de la ganadería de la región estaba acaparada por muy pocos propietarios. El estudio del Catastro de Ensenada nos permite aproximarnos al grado de concentración de la propiedad pecuaria. Hemos escogido como muestra cuatro municipios que contaban con una importante cabaña ganadera. Para una aproximación a la concentración de la propiedad ganadera nos hemos centrado en el ganado vacuno que como vimos con anterioridad constituye la especie más significativa de la ganadería regional. Las localidades escogidas son Carmona, Écija, Alcalá de los Gazules y Jerez de la Frontera, en las que existe una importante clase de propietarios locales, todas ellas con una importante cabaña ganadera ${ }^{14}$ y situadas tanto en zonas de sierra como de campiña. Las Respuestas Particulares del Catastro de Ensenada, no han permitido identificar a los grandes ganaderos de cada localidad, mientras que los Mapas ${ }^{15}$ nos dan la totalidad de cabezas de cada especie existentes en el municipio. Del cruce de ambos datos resulta que: en Écija, nueve ganaderos son propietarios del $26 \%$ del ganado vacuno municipal; en Carmona, once ganaderos poseen el $43 \%$ del vacuno; en Alcalá de los Gazules, diez propietarios tienen el $56 \%$ del ganado vacuno del término y, por último, en Jerez, veinticuatro ganaderos son propietarios del $52 \%$ del vacuno de la localidad.

Otra muestra del elevado grado de concentración de la propiedad de la ganadería en la Baja Andalucía lo encontramos en el censo ganadero de 1865 en el que se contabilizan 745 propietarios de más de 100 cabezas de ganado vacuno en toda España, de los que el 67,5\% se localizan en Andalucía Occidental, sólo en las provincias de Cádiz y Sevilla se sitúan el 50,6\% de los mismos.

Para realizar este estudio hemos partido de una muestra de 322 ganaderías que abarcan desde 1366 hasta 1931. Dichas ganaderías pertenecen a las provincias de Sevilla y Cádiz y están localizadas en todo tipo de comarcas, campiñas, marismas y sierras. El criterio elegido a la hora de su selección es el de su tamaño, especialmente referido al número de cabezas de vacuno que poseen ${ }^{16}$. Estas ganaderías se han seleccionado entre fuentes muy diversas: documentación de carácter fiscal -padrones fiscales medievales, Catastro de Ensenada, declaraciones juradas, amillaramientos...-, inventarios de bienes de carácter notarial, documentación privada... La composición de estas ganaderías se recoge en el cuadro 2 .

14 En total, el ganado vacuno de los cuatro términos municipales superaba el $11 \%$ del total regional.

15 INE: Censo ganadero Castilla...

16 Hemos seleccionado a los ganaderos que poseen más de 100 cabezas de ganado vacuno.

Hispania, LXV/3, núm. 221 (2005) 1023-1042 
CUADRO 2. ESTRUCTURA DE LAS GRANDES GANADERÍAS EN LA BAJA ANDALUCÍA. SIGLOS XIV AL XX

\begin{tabular}{|l|c|c|c|}
\hline Especies & $\mathbf{N}^{\mathbf{o}}$ de cabezas & Unidades ganaderas & $\begin{array}{c}\text { \% de cada especie sobre total } \\
\text { Unidades Ganaderas }\end{array}$ \\
\hline Vacuno & 98.705 & $83.899,3$ & 55,5 \\
Caballar & 17.089 & $17.089,0$ & 11,3 \\
Mular & 733 & 733,0 & 0,5 \\
Asnal & 8.394 & $6.715,2$ & 4,4 \\
Ovino & 303.693 & $30.369,3$ & 20,1 \\
Caprino & 33.690 & $3.369,0$ & 2,2 \\
Porcino & 44.633 & $8.926,6$ & 6,0 \\
\hline TOTAL & & $151.101,4$ & 100,0 \\
\hline
\end{tabular}

Fuentes: ver cuadro 3

El rasgo más destacado de estas ganaderías es el predominio absoluto del ganado vacuno, que representa más de la mitad de las unidades ganaderas de estas grandes ganaderías. En segundo lugar se sitúa el ganado ovino que representa el $20 \%$ y el caballar más del $11 \%$. Esto hace que las tres especies aporten casi el $90 \%$ del peso en vivo de toda esta cabaña ganadera. Se observa pues una fuerte vinculación de estas ganaderías con la agricultura: vacuno para la tracción, caballar para la trilla y ovino para el abonado y la renta. El ganado jugaba un papel muy importante en el trabajo agrícola de la explotación, al mismo tiempo que era una fuente de ingresos monetarios muy importante dada su fácil comercialización en alguna de las grandes ferias de la región (Mairena del Alcor, Santiponce, Villamartín...).

Los seis siglos que median entre la primera de las ganaderías escogidas y la última, nos permiten establecer una cierta evolución para poder aproximarnos mejor a la evolución de la estructura de las grandes ganaderías.

El primer rasgo a destacar en este tipo de ganaderías es el gran tamaño que formaban las piaras de las distintas especies en manos de cada ganadero. En segundo lugar, se aprecia una clara tendencia al incremento de las dimensiones de las explotaciones ganaderos a lo largo de todo el período.

Este incremento del tamaño medio de las cabañas ganaderas de los grandes propietarios se corresponde claramente con el crecimiento continuo de las superficies medias de los latifundios andaluces y constituye otro indicador más acerca del proceso de implantación de una burguesía agraria en Andalucía Occidental, que habría impedido el desarrollo de la campesinización, tal como se había dado en otras regiones europeas y españolas. El mantenimiento de estas importantes piaras de ganado fue un importante estímulo que tuvieron los grandes labradores y ganaderos a la hora de disputar a los pequeños campesinos el disfrute de las tierras comunales y de los usos colectivos. 
CUADRO 3. EVOLUCIÓN DE LA ESTRUCTURA DE LAS

GRANDES GANADERÍAS 1366-1932

\begin{tabular}{|l|c|c|c|c|c|c|c|r|}
\hline Períodos & Vacuno & Caballar & Mular & Asnal & Ovino & Caprino & Porcino & U. G. \\
\hline $1366-151917$ & 156 & 7 & 1 & 6 & 508 & - & 200 & 236,2 \\
$1598-171718$ & 428 & 51 & 3 & 33 & 4.165 & 720 & 353 & $1.003,3$ \\
$1730-181919$ & 286 & 51 & 4 & 33 & 1.330 & 532 & 236 & 557,9 \\
$1820-1898^{20}$ & 350 & 88 & 12 & 45 & 893 & 323 & 186 & 592,3 \\
$1900-1932^{21}$ & 633 & 64 & 13 & 31 & 872 & 373 & 508 & 866,0 \\
\hline Total & 340 & 64 & 9 & 36 & 1.184 & 425 & 425 & 601,9 \\
\hline
\end{tabular}

(número medio de cabezas por ganadero22)

\section{LOS GRANDES GANADEROS}

En Andalucía occidental, durante el Antiguo Régimen, la propiedad de la mayor parte de la tierra estaba vinculada a la nobleza y a determinadas instituciones eclesiásticas, quedando de este modo al margen del mercado. Los labradores para acceder al uso de la tierra tenía que recurrir al contrato de arrendamiento con los terratenientes. En Andalucía occidental las modalidades de contrato más frecuentes eran los contratos a corto plazo, entre tres y cuatro años por término medio, y, a diferencia de otras regiones españolas, el arrendamiento de grandes fincas sin parcelar, lo que reducía los costes de gestión para el propietario y presentaba un menor riesgo ${ }^{23}$.

17 Corresponde a los padrones fiscales de 1484-1519 (CARMONA RuIZ: La ganadería...), la ganadería de 1366 es la de García Santillán (COLLANTES DE TERÁN: «Le latifundium sevillan aux XIV ${ }^{e}$. et XV e $^{e}$ s. Ebauche d'une problematique», Melanges de la Casa de Velázquez XII, (1976), pp. 101-125).

18 Los datos proceden de inventarios notariales de bienes de la primera mitad del siglo XVII, que me han sido facilitados por el profesor Dr. Aguado de los Reyes, así como de una serie de ganaderías monásticas de 1715-17 (ACS, Mesa Capitular, lib. ) y de la ganadería del colegio S. Hermenegildo, de los Jesuitas de Sevilla, tras su quiebra en 1646 (AMS, Papeles del Conde del Águila, lib.).

19 Incluye las ganaderías procedentes de inventarios notariales de bienes, las contenidas en la Respuestas Particulares al Catastro de Ensenada de varios municipios y las de las declaraciones juradas de 1817-19 de varios municipios.

20 Inventarios notariales de bienes, amillaramientos de varias localidades y declaraciones juradas de 1897.

21 Estadística de la Unión de Criadores de Toros de Lidia (GARCía AlEAS, M.: El toro de lidia en la plaza de la economía nacional, Madrid, 1932).

22 La media se ha calculado sobre el número de ganaderos que poseen, dentro de cada especie, cabezas de ganado de la misma.

23 BoUtelou, E.: «Observaciones sobre las grandes labores de Andalucía, e ideas sobre las utilidades y perjuicios que resultan al Estado y a la Agricultura de la excesiva extensión de los grandes cortijos", Semanario de Agricultura y Artes, 590 (1808), pp. 265-270. 
Las elevadas rentas que implicaba el arrendamiento de estas grandes fincas y las duras garantías exigidas por los propietarios o sus administradores hacían que la posibilidad de arrendar estas grandes explotaciones sólo estuviese al alcance de muy pocos vecinos del municipio. Precisamente, dado su corto número, era frecuente que algunos colonos pudiesen llevar en arrendamiento, al mismo tiempo, varias de estas grandes propiedades, convirtiéndose, así, en grandes colonos. Esta condición de gran colono solía estar asociada a unas pocas familias de cada término municipal y se iban trasmitiendo de padres a hijos, no siendo extraño que grandes fincas permaneciesen arrendadas, a pesar del corto plazo de los arrendamientos, a miembros de la misma familia durante largos períodos de tiempo.

Para los grandes labradores, apartados de la propiedad de la tierra y sujetos al azar de una subasta, que era la forma habitual de contratar el arrendamiento de las grandes explotaciones, la propiedad del ganado era lo que le permitía mantener su status privilegiado dentro del municipio. Sólo los propietarios de un gran número de cabezas de labor podían acceder al arrendamiento de los grandes cortijos, cuya superficie requería una importante cabaña de ganado de labor para su explotación. Los grandes labradores aseguraban la reproducción de su ganado de labor manteniendo un cierto número de hembras de vientre que produjesen cada año las crías necesarias para reponer el ganado de labor que se fuese eliminando. Los excedentes de la sustitución del ganado de labor se comercializaban como crías o, en su caso, como toros de lidia para los espectáculos taurinos ${ }^{24}$.

El ganado se convertía para el gran labrador en una reserva de capital, dado su alejamiento de la propiedad de la tierra y a la ausencia de otras alternativas de inversión. En muchas particiones notariales de bienes se observa como el ganado se utiliza para pagar las deudas contraídas por el difunto o los derechos reales generados por la herencia. El ganado se convertía, así, en una parte del patrimonio del que se podía disponer dada su mayor liquidez. Dentro del ganado se enajenaba primero el ganado de renta y sólo en caso de mayor necesidad el de labor, especialmente las yuntas de bueyes, bien más preciado por los labradores, sobre todo si no eran terratenientes. También, el ganado se podía pignorar como garantía de una deuda.

Los diferentes procesos desamortizadores que tuvieron lugar en el siglo XIX sacaron al mercado una gran cantidad de tierras. Los grandes labradores andaluces tuvieron una participación muy activa en la adquisición de las tierras procedentes de los propietarios del Antiguo Régimen. Esto les permitió acceder a la condición de grandes propietarios, en muchos casos, de las tierras de las que con anterioridad habían sido colonos.

24 LÓPEZ MARTÍNEZ, Antonio Luis: Ganaderías de lidia y ganaderos. Historia y economía de los toros de lidia en España, Sevilla, 2002.

Hispania, LXV/3, núm. 221 (2005) 1023-1042 


\section{Los grandes ganaderos hasta el siglo XVII}

Desde la primera ganadería de la que tenemos noticias, la de Fernán García Santillán de mediados del siglo XIV, que explotaba más de 400 hectáreas en Lebrija y era propietario de una extensa ganadería con cerca de 100 bueyes de labor ${ }^{25} \mathrm{y}$, continuando, con las que se observan en los padrones fiscales de finales del siglo XV y comienzos del XVI, se aprecia una estrecha relación entre la agricultura y la ganadería. Esto lleva a Carmona $\mathrm{Ruiz}^{26}$ a afirmar que al final de la Edad Media era poco frecuente la figura del ganadero puro. La misma autora destaca el carácter protagonista que tenía la oligarquía local en la propiedad de las grandes piaras de ganado gracias a que tenía el control de acceso a los pastos comunales y al cierre de sus explotaciones a los ganados vecinales como se denuncia en las pesquisas judiciales estudiadas por el profesor Ladero ${ }^{27}$.

La información que hemos encontrado sobre ganaderías para el siglo XVI es prácticamente nula. Alguna mejor suerte hemos tenido en el caso del siglo XVII (1594-1717), para el que hemos localizado a 14 grandes ganaderos. La mitad de ellos corresponden a instituciones monásticas y regulares y la otra mitad corresponden a particiones de bienes de particulares vecinos de Sevilla.

La zona geográfica que abarcan es extensa e incluye dos monasterios de la Sierra Norte sevillana, la cartuja de Jerez y el resto de los ganaderos son vecinos de Sevilla, estando sus ganados en localidades próximas, Utrera, Dos Hermanas, Alcalá de Guadaira, Aznalcázar... Un rasgo común a todos ellos es el de ser de labradores, ya sea en tierras de su propiedad, los eclesiásticos, ya sea en régimen de arrendamiento los laicos. También en este período la ganadería muestra una estrecha relación con la agricultura como indica la propiedad de 1.636 bueyes, cuyo destino, como ya se ha especificado es la labor.

Hay que destacar las importantes diferencias que se aprecian entre los ganaderos laicos y los eclesiásticos. La presencia entre estos últimos de instituciones tan importantes como la Cartuja de Jerez, los monasterios jerónimos de Santiponce y Buenavista y del colegio S. Hermenegildo de los jesuitas sevillanos, que figuran como las instituciones monásticas más ricas de todo el reino de Sevilla, hace que su papel en la muestra estudiada sea claramente determinante. Estas instituciones son propietarias de varios cortijos que labran directamente y cuentan con dehesas para el mantenimiento del ganado. Sus propiedades se elevan a dos o tres mil hectáreas, además de las que suelen llevar en arrendamiento, lo que da unas considerables dimensiones a sus explotaciones agrarias.

Entre los propietarios seglares de ganado, una característica a destacar es la de su pertenencia a la oligarquía municipal sevillana. De los siete estudiados,

is COllantes de TerÁN, A. (1976): «Le latifundium sevillan aux XIV'. et $\mathrm{XV}^{\mathrm{e}}$ s. Ebauche d'une problematique», Melanges de la Casa de Velázquez (XII): 101-125.

26 La ganadería..., p. 340-341.

27 «Donadíos en Sevilla. Algunas notas sobre la propiedad de la tierra hacia 1500», Archivo Hispalense, 181 (1976), pp. 19-91. 
cuatro están relacionados con la administración municipal, un veinticuatro, dos jurados y un secretario y otros dos con el Santo Oficio (un secretario y un familiar). Su potencial económico es menor que el de los eclesiásticos. Suelen ser propietarios o llevar en arrendamiento uno o dos cortijos y alguna hacienda de olivar, entre las tierras que explotan no figuran dehesas, lo que implica la utilización de las dehesas comunales para el mantenimiento de su ganado.

\section{Siglo XVIII}

A mediados del siglo XVIII entre los municipios que tenían una importante cabaña ganadera se pueden distinguir tres categorías atendiendo a la presencia o ausencia en ellos de grandes propietarios de ganado. En primer lugar, encontraríamos dos localidades en las que se produce una importante concentración de grandes ganaderos, son las ciudades de Sevilla y Jerez. La mayor concentración debería darse en Sevilla. Su importancia deriva del hecho de que sus vecinos apareciesen, según el Catastro de Ensenada, como propietarios de 19.000 cabezas de vacuno.

Aunque no se dispone de las Respuestas Particulares de la ciudad de Sevilla, hemos localizado los inventarios de bienes de 21 grandes propietarios de ganado sevillanos correspondientes al siglo XVIII. Los datos de los mismos nos revelan su gran importancia social. Entre ellos hay ocho títulos nobiliarios y otros cuatro relacionados directamente con ellos (hijos, hermanos o yernos), otros cinco corresponden a apellidos muy notorios de la ciudad, Ibarburu, Maestre y Esquivel, todos ellos, caballeros maestrantes y sólo cuatro de los grandes ganaderos no ostentan atribución social reconocida. Todos los propietarios de ganado son labradores que cultivan tierras propias o en arrendamiento. De estos grandes ganaderos, nueve cultivan totalmente o en buena parte tierras que son de su propiedad, el resto son predominantemente colonos. Hemos conseguido calcular la superficie que cultivaban nueve de estos grandes ganaderos, que es aproximadamente de unas 15.000 hectáreas de cereal, además varios de ellos poseen olivares y algunas viñas.

La cabaña ganadera está dominada por el ganado lanar en número, casi 40.000 cabezas, casi 2.000 de media por ganadero, y por el vacuno, $7.382 \mathrm{ca}$ bezas, en las unidades ganaderas. El ganado vacuno propiedad de estos ganaderos equivale al $40 \%$ del ganado perteneciente a los vecinos de Sevilla. En el ganado vacuno como en el resto de la cabaña se distinguen perfectamente las dos categorías de ganado, el de labor, 2.137 bueyes y el de granjería, que es el resto. La importancia de los bueyes, unos 100 por término medio correspondientes a cada ganadero, unido a la frecuente presencia frutos de las cosechas en graneros y almacenes nos confirma el carácter de labradores que tenían los grandes ganaderos sevillanos. Del resto de animales que integran la cabaña ganadera, hay que señalar las aproximadamente 1.500 cabezas de ganado ca- 
ballar, más de la mitad son yeguas para la trilla. En definitiva los grandes ganaderos vecinos de la ciudad de Sevilla ostentaban una doble categoría, la de grandes labradores por una parte y, por otra, la de criadores de ganado. La estructura de su cabaña ganadera, en la que destacan hembras reproductoras y crías de todas las edades nos muestra como el ganado necesario para la labor era reproducido y criado, en su mayoría, por los mismos labradores y, en buena parte, al margen de las ferias comarcales próximas.

Conocemos, gracias a las Respuestas Generales, la mayoría de las dehesas en las que pastaba el ganado de los vecinos de Sevilla. Las dehesas pertenecientes a los propios de la ciudad estaban situadas en Aznalcázar y Puebla del Río en las Marismas, Castilblanco y El Pedroso en la Sierra Norte, Villamartín en el Campo de Matrera y Escacena y Tejada en el Campo de Tejada. Las dehesas del común se situaban, principalmente, en las Islas Mayor y Menor en las Marismas del Guadalquivir. Por su parte la mayor parte de las tierras de cultivo que labraban los grandes ganaderos sevillanos se extendían por Utrera, Alcalá de Guadaira, Dos Hermanas, Carmona y algunos municipios del Aljarafe.

Mucho más completa es la información que hemos localizado sobre los grandes ganaderos de Jerez gracias a la conservación de las Respuestas Particulares de este municipio y a la conservación de algunos inventarios notariales de bienes. Los vecinos de Jerez eran propietarios de más de 12.000 cabezas de ganado vacuno, de los que una buena parte, más del $70 \%$, pertenecían a veinticuatro grandes ganaderos propietarios, según el Catastro, de más de 100 cabezas de vacuno. En este caso, la mayoría del ganado pastaba en el propio término municipal para lo que contaba con más de 40.000 hectáreas de pasto, unas 12.000 hectáreas de monte y 56.000 hectáreas de sembradura cultivadas al tercio, lo que permitía el aprovechamiento de casi 19.000 hectáreas de manchón, así como las rastrojeras de otras tantas hectáreas sembradas de cereal.

Las respuestas particulares de Jerez nos permiten identificar a veinticuatro grandes propietarios de ganado ${ }^{28}$. De estos ganaderos, siete pueden ser considerados como grandes terratenientes con más de 250 hectáreas de superficie, entre todos poseen 8.685 hectáreas, de ellos dos son comunidades de regulares, Cartuja y convento de Santo Domingo. Sólo la Cartuja de Jerez era propietario de más de 3.000 hectáreas. Además hay otros diez ganaderos que pueden ser considerados como medianos propietarios, con una media de unas 25 hectáreas cada uno $\mathrm{y}$, por último, hay otros siete ganaderos que carecen de inmuebles rústicos.

En general, la cabaña de estos grandes ganaderos estaba estrechamente relacionada con la agricultura, como prueba la existencia de un gran número de bueyes, más de 3.500 , en su mayor parte destinados a la arada, así como de

28 En un estudio realizado por GONZÁLEZ BELTRÁN: Honor, riqueza y poder: los Veinticuatros de Jerez de la Frontera en el siglo XVIII, Jerez de la frontera, 1998, resulta, según los inventarios notariales de sus bienes, que 16 de los 54 veinticuatros analizados son propietarios de ganado, incluso alguno de ellos podría ser clasificado como gran ganadero. 
otro animal también vinculado a las faenas agrícolas como eran las yeguas para la trilla. Lo que hace que casi todos estos ganaderos, incluidos los dos establecimientos religiosos, sean en realidad grandes labradores, tanto en tierras propias como en las que llevan en arrendamiento y que buena parte de su ganadería sea, en realidad, ganadería auxiliar de la agricultura.

También estos grandes ganaderos poseían una importante ganadería de granjería, con más de 4.000 vacas de vientre, casi 27.000 ovejas, unas 6.500 cabras y más de 3.000 cerdos. Algunos de estos ganaderos no parecen estar relacionados con la agricultura, especialmente tres de ellos a los que no se les consignan bueyes en propiedad, aunque si tienen vacas. Habrían de ser considerados como ganaderos puros, similares a los que vamos a encontrar más frecuentemente en las zonas de la sierra gaditana.

La segunda categoría la constituyen aquellas localidades en las que se produce una mediana concentración de grandes propietarios de ganado. Esta concentración puede ser debida a la importante actividad agrícola que se desarrolla en ellas, caso de las localidades de la campiña sevillana, Écija, Carmona, Utrera, Morón..., o bien en localidades de fuerte vocación ganadera y suficientemente alejadas de las grandes ciudades que por ello pierden buena parte de su influencia, como es el caso de las localidades de la Sierra de Cádiz, Alcalá de los Gazules y Medina Sidonia. En todos estos casos, el número de grandes ganaderos se sitúa en torno a la decena y están integrados, principalmente por miembros de la oligarquía local. Entre los grandes ganaderos de Écija figuran ocho nobles, de los que cuatro son regidores, en Utrera aparecen siete nobles de los que tres son regidores, en Alcalá de los Gazules hay seis eclesiásticos y tres nobles y en Medina Sidonia son once los nobles y de ellos hay cinco regidores ${ }^{29}$. Esta importante oligarquía local controla el acceso a los pastos comunales y cierra el paso a la penetración de los grandes ganaderos de las ciudades de Jerez y Sevilla. Así, mientras que los grandes ganaderos sevillanos y jerezanos reparten sus ganados en varios términos municipales, entre los que dichos ganados se desplazan varias veces a lo largo del año, los grandes ganaderos de las ciudades intermedias concentran su cabaña ganadera en un sólo término municipal sobre el que ejercen una fuerte influencia gracias al entramado de poder que crean controlando los órganos de poder municipal ${ }^{30}$ y llevando a cabo con los miembros de sus familias una fuerte endogamia.

29 SÁNCHEZ LORA, José Luis: Capital y conflictividad social en el campo andaluz: Morón de la Frontera (1670-1800), Sevilla, 1998, pone de manifiesto la coincidencia de intereses que se producía entre la administración municipal y los intereses de los grandes labradores-ganaderos, dado que solían ocupar los cargos de justicias y capitulares de la villa.

30 VIllalonga SeRRANO: Organización y coyuntura económica en Utrera en los comienzos del siglo XVI, Sevilla, 1999, tesis de licenciatura inédita, ha puesto de manifiesto la correspondencia existente entre el nivel de cuantía de los vecinos de Utrera y el acceso a los cargos municipales. En 1493 casi los dos tercios de los vecinos cuya cuantía superaba los 100.000 maravedíes ocupaban cargos municipales frente a sólo el $3 \%$ de los vecinos cuya cuantía no alcanzaba los 50.000 maravedíes.

Hispania, LXV/3, núm. 221 (2005) 1023-1042 
En Carmona los grandes propietarios de ganado son, salvo el caso del colegio de los jesuitas de la localidad que posee más de 1.100 hectáreas, medianos propietarios de tierras -cuatro propietarios poseen menos de 300 hectáreas-, o bien carecen por completo de tierras, seis de ellos. Sin embargo, llevan en arrendamiento grandes extensiones de tierras, así siete de ellos llevan en arrendamiento 5.250 hectáreas. Por tanto, se trata en su mayoría de grandes labradores, estando una buena parte de su ganado relacionada con su actividad agrícola. Similar es el caso de Écija, donde figuran diez grandes ganaderos, de los que cuatro poseen más de 5.500 hectáreas -4.000 de sembradura y 1.500 de pastos-, pero seis carecen de este tipo de propiedades, si bien casi todos ellos son propietarios de tierras de olivar, en total más de 1.000 hectáreas.

En los casos de Utrera y Morón la categoría de colonos de estos grandes ganaderos es aún más acusada. En Utrera de los ocho grandes ganaderos localizados, cinco no poseen inmuebles rústicos alguno y los otros tres sólo tienen parcelas de olivar ${ }^{31}$. La composición de su cabaña en la que predomina el ganado vacuno, todos ellos tienen bueyes, en total 536, y la importante presencia de yeguas para la trilla nos lleva a considerarlos como grandes labradores. Para mantener su ganado han de recurrir, sin duda, a los pastos comunes del municipio y a tomar tierras en arrendamiento para su labranza mediante el sistema de cultivo al tercio. En Morón hemos localizado a seis propietarios con más de 100 vacunos, pero sólo uno tiene tierras de sembradura, 400 ha, mientras que el resto sólo poseen algunas parcelas de olivar, Sin embargo, dada la composición de su cabaña ganadera, con 330 bueyes, hay que considerarlos como grandes labradores, que deberían de llevar en arrendamiento tierras del duque de Osuna ${ }^{32}$, señor del municipio y propietario de casi 9.000 hectáreas en el término municipal.

Para mantener sus importantes cabañas ganaderas en estas localidades se utilizan tanto los pastos como los barbechos y los residuos de las cosechas, para cuya preservación se recurren a los cerramientos, siendo muy importante la superficie cerrada ${ }^{33}$. En Carmona hay dieciocho cortijos cerrados que en total ocupan unas 8.000 hectáreas de superficie, mientras que los baldíos son 4.000

31 En los cuatro inventarios notariales de bienes de ganaderos utreranos localizados para el siglo XVIII se confirma el carácter de colonos de los mismos. En los cuatro casos estudiados, los ganaderos aparecen como propietarios de algunas decenas de hectáreas de olivar y colonos de cortijos que ocupan entre 600 y 1.500 ha por cada uno de ellos. Los cuatro poseen más de 400 bueyes de labor y dos de ellos son propietarios de numerosas vacas de vientre y crías de ganado vacuno.

32 Existen importantes coincidencias entre los apellidos de estos grandes ganaderos y los de los mayores arrendatarios de las tierras del duque de Osuna en Morón en 1730 (CONTRERAS, Jaime: "La explotación del patrimonio del duque de Osuna» en ARTOLA, BERNAL y CONTRERAS: El latifundio. Propiedad y explotación, ss. XVIII-XX, Madrid, 1978.

33 Los ayuntamientos llevaban la gestión de los baldíos municipales y eran, junto a la Corona, los que concedían licencias de cerramiento para las tierras de propiedad privada. De ahí, el interés de los grandes labradores en ocupar los principales cargos municipales.

Hispania, LXV/3, núm. 221 (2005) 1023-1042 
hectáreas. En Écija hay 20.000 hectáreas de dehesas, de ellas 12.000 son comunes y las autoridades consideran cerrada cualquier tierra con la única condición de pagar medio real por fanega de tierra, además cultivan al tercio más de 51.000 hectáreas que le suponen 17.000 de manchón anuales, más el aprovechamiento de otras tantas hectáreas de rastrojera. En Utrera hay 11.000 hectáreas cerradas, 16.500 hectáreas de baldíos comunales y se cultivan al tercio 55.000 hectáreas, que suponen importantes superficies de manchones y rastrojeras aptas para los ganados. En Morón, además de 6.500 hectáreas cerradas, hay 60.000 hectáreas de tierras con sistemas de cultivo muy extensivos, tercio $y$ rozas que permiten un importante aprovechamiento ganadero.

En el caso de los grandes propietarios de ganado de los municipios serranos de Alcalá de los Gazules y Medina Sidonia, aparecen ciertas diferencias respecto a los que se localizan en la campiña sevillana. En primer lugar destaca su número, diecisiete en Medina Sidonia y diez en Alcalá de los Gazules. En cuanto a la naturaleza del ganado hay que destacar la importancia del ganado menor, 18.000 ovejas, 4.500 cabras y 5.500 cerdos, si bien el ganado vacuno con unas 7.500 cabezas es bastante considerable. Otra diferencia que se aprecia es su menor vinculación con la agricultura, dado el menor desarrollo que alcanza esta actividad en estos municipios. Aunque en Medina Sidonia casi todos los grandes ganaderos poseen tierras en propiedad, sólo puede ser considerados como medianos propietarios, 1.100 hectáreas para diecisiete ganaderos, con propiedades que oscilan entre 35 y 185 hectáreas, mientras que en Alcalá de los Gazules sólo poseen en total 170 hectáreas. De aquí que para mantener sus grandes rebaños estos ganaderos han de recurrir a los pastos de las dehesas del común que son muy abundantes, casi 25.000 hectáreas entre ambos términos municipales. También son importantes los cerramientos que abarcan unas 13.000 hectáreas de superficie. Esta fuerte privatización de los espacios comunes característica de estas localidades serranas es posible gracias al fuerte control que sobre el poder municipal ejercen los propietarios de ganado, que configuran como vimos una potente oligarquía local.

La localización de algunos inventarios notariales de bienes -cinco de Medina Sidonia y uno de Alcalá de los Gazules- perfila mejor la naturaleza de estos grandes ganaderos serranos. Es cierto que todos ellos aparecen como propietarios de bueyes, pero su corto número, de 20 a 40 yuntas, unido a un reducido número de yeguas, entre 20 y 30 , parece indicarnos que si bien son labradores, no parece ser esta su actividad principal, sino la de ganaderos, como pone de manifiesto un elevado número de vacas de vientre y del resto del vacuno en general, muy superior a la que podría considerarse necesaria para la reproducción de los bueyes.

Una posición intermedia es la de aquellas localidades en las que sólo hay tres o cuatro grandes ganaderos. Este es el caso que se ha podido analizar en las localidades de Lebrija y Lora del Río, ambos municipios en la vega del Guadalquivir. En ambos casos la figura del gran ganadero existente es similar, se trata 
de un labrador que tiene unas parcelas de olivar y lleva en arrendamiento tierras de cereal. Su ganadería está estrechamente relacionada con la agricultura, como se observa en el caso de Lebrija, donde tres ganaderos poseen 227 bueyes y unas 100 yeguas para las labores agrícolas, amén de una mediana ganadería de granjería con 1.800 ovejas y. 140 vacas de vientre. La importancia de los grandes ganaderos en Lora del Río es algo menor, tanto en los que se refiere al ganado de labor como al de granjería. En ambos municipios la importancia de los baldíos del común es grande, 8.700 hectáreas en Lora del Río y todavía mayor en Lebrija, casi 14.000 hectáreas, teniendo, además, comunidad de pastos con Trebujena.

Por último, están aquellas localidades, que a pesar de figurar con una considerable cabaña ganadera, en las Respuestas Particulares no aparecen grandes ganaderos o sólo figura un muy reducido número de ellos. Este tipo de localidades las encontramos en las proximidades de Sevilla, caso de Alcalá de Guadaira, Guillena o Puebla del Río, en las que no aparece ningún ganadero con más de 100 cabezas de vacuno o Castilblanco y Dos Hermanas, en la que sólo aparece uno de estos grandes ganaderos. La ausencia de estos grandes ganaderos hay que atribuirla a la fuerte influencia que ejercían los grandes propietarios de la ciudad de Sevilla en las localidades de su radio de acción más próximo. Eran estos ganaderos los que ocupaban las mejores y mayores extensiones de pastos, mientras que a los ganaderos locales sólo se les permitía tener piaras pequeñas y medianas. En estas localidades los miembros de la oligarquía sevillana eran propietarios o llevaban en arrendamiento grandes extensiones de tierras, de las que excluían a los labradores locales que no podían pujar por falta de medios en las subastas para el arrendamiento de las grandes fincas. Además se beneficiaban de la situación ventajosa de la que disfrutaban por ser vecinos de Sevilla, lo que les permitía aprovecharse de las tierras comunales de otros municipios de la jurisdicción de Sevilla ${ }^{34}$ y de las comunidades de pastos que Sevilla tenía con otros municipios.

Del repaso a las Respuestas Particulares disponibles en los archivos municipales de la Baja Andalucía, queda de manifiesto la gran importancia que alcanzó la figura del gran ganadero. En las seis localidades estudiadas en las que hay mayor concentración de ganado -Alcalá de los Gazules, Carmona, Écija, Jerez, Medina Sidonia y Utrera- con el $22 \%$ de todo el ganado vacuno del Reino de Sevilla, más del $38 \%$ del ganado vacuno existente en estos municipios es propiedad de 80 grandes ganaderos. Incluso en algunos municipios, Jerez y Alcalá de los Gazules, los grandes ganaderos poseen más de la mitad del ganado vacuno del municipio. Aunque la propiedad de la tierra en manos de estos grandes propietarios no es considerable, sin embargo, casi todos ellos tienen la con-

34 El enfrentamiento del Ayuntamiento de Aznalcázar con un vecino de Sevilla por meter su ganado en los baldíos del pueblo ha sido estudiado por García Fuentes, L.: Aznalcázar en su.bistoria, Sevilla, 1999. 
dición de grandes labradores, llevando en arrendamiento grandes extensiones de tierras, lo que permite una perfecta integración de las actividades agrícolas y pecuarias. Buena parte de su ganadería está orientada a la agricultura, bien como bueyes de arada, bien como yeguas para la trilla, si bien el ganado de granjería es bastante considerable, sobre todo como vacas de vientre, ovejas y cerdos, el ganado cabrío, sólo tiene importancia en algunas comarcas. La importancia social y administrativa que estos grandes ganaderos desempeñan en los diferentes municipios, gran cantidad de nobles y el cargo de regidor en los respectivos concejos que ostentan muchos de ellos les permite el control de los usos y bienes comunales, así como les facilita el disfrute de los mismos, excluyendo, mediante el cerramiento, del acceso a los pastos a la mayor parte de los vecinos.

\section{CUADRO 4. CABAÑAS GANADERAS DE ALGUNOS CONVENTOS DEL REINO DE SEVILLA, 1594-1767}

\begin{tabular}{|l|l|c|c|c|c|c|c|c|c|}
\hline Conventos & Localidad & Año & Bueyes & vacuno & caballar & asnos & ovejas & cabras & cerdos \\
\hline S. Isidoro & Santiponce & 1594 & 68 & 185 & 34 & 18 & 2.100 & 450 & \\
\hline S. Hermen & Sevilla & 1646 & 441 & 800 & 165 & 177 & 13.500 & & \\
\hline Jesuitas & Arcos & 1695 & 58 & 389 & 41 & 31 & & & \\
\hline Cartuja & Jerez & 1717 & 300 & 1.100 & 182 & 40 & 1.200 & & 50 \\
\hline S. Isidoro & Santiponce & 1717 & 100 & 487 & 46 & & 3.000 & & 350 \\
\hline S. Jerónim & Sevilla & 1717 & 183 & 260 & 54 & & 3.500 & & 350 \\
\hline Basilios & Constantina & 1717 & 60 & 90 & 28 & & 1.450 & & \\
\hline Cartuja & Cazalla & 1717 & 80 & 150 & 17 & & 3.650 & & \\
\hline Cartuja & Sevilla & 1755 & & 356 & 146 & & 1.541 & 263 & 100 \\
\hline Cartuja & Jerez & 1755 & 453 & 773 & 231 & 140 & 1.734 & 990 & 455 \\
\hline S. Domin & Jerez & 1755 & 100 & 136 & 49 & 34 & 1.035 & & 25 \\
\hline Jesuitas & Carmona & 1755 & & 258 & 54 & 48 & 2.460 & & 90 \\
\hline S. Isidoro & Santiponce & 1755 & & 150 & 60 & 20 & 1.700 & & 70 \\
\hline Jerónimos & Lucena Pt. & 1755 & 63 & 102 & 22 & 7 & 1.230 & 36 & 310 \\
\hline Jerónimos & Lucena Pt. & 1764 & 80 & 120 & & 30 & 550 & 350 & 560 \\
\hline Jesuitas & Jerez & 1767 & 97 & 75 & 53 & 53 & 2.016 & & \\
\hline Jesuitas & Arcos & 1767 & 140 & 406 & 48 & 18 & 3.370 & & 164 \\
\hline Becas & Sevilla & 1767 & & 204 & & & 2.076 & & \\
\hline Cartuja & Jerez & 1807 & 368 & 826 & 187 & 121 & 1.882 & 1.185 & 326 \\
\hline
\end{tabular}

Fuentes: Archivo de la Catedral de Sevilla, Fondo Histórico General, lej. 10; Archivo Municipal de Sevilla, Papeles del Conde del Águila; tomo 12; Archivo de la Catedral de Sevilla, Mesa Capitular, libros 1165B, 1166 y 1172; Archivo Municipal de Jerez, Catastro de Ensenada; Libro del Mayor Hacendado del Catastro de Ensenada; Archivo Arzobispal de Sevilla, Regulares 8;

Hay que destacar la importancia que durante el Antiguo Régimen alcanzaron las ganaderías pertenecientes a algunos monasterios y conventos andaluces. La 
documentación disponible ha permitido localizar a veintidós institutos regulares que fueron grandes propietarios de ganado. Todos estos conventos ganaderos tuvieron la condición, a su vez, de grandes labradores ${ }^{35}$. En su mayoría cultivaron sus propias tierras, aunque, en ocasiones, algunos no desdeñaran el tomar tierras en arrendamiento para redondear mejor sus explotaciones agrarias con el fin de obtener mayores beneficios. La composición de sus cabañas (Cuadro 4) nos muestra una ganadería muy relacionada con la agricultura —-bueyes y yeguas-, pero en la que el ganado de granjería —ovejas y vacas- jugó un papel muy destacado.

\section{Siglo XIX}

Durante la primera mitad del siglo XIX se van a producir una serie de cambios importantes en la naturaleza de los grandes ganaderos. Estos cambios están relacionados con la denominada crisis del Antiguo Régimen y que supuso la quiebra de algunas de las instituciones que habían prevalecido durante el anterior período. Los más afectados fueron los monasterios y conventos de regulares, que como hemos visto habían adquirido una gran importancia como labradores y ganaderos, sobre todo en el siglo XVIII. La Guerra de la Independencia vino a romper esta boyante situación, desplazados en numerosas ocasiones de sus conventos tuvieron que interrumpir su actividad como labradores de sus tierras, que posteriormente serían puestas en venta durante los procesos desamortizadores. Todo ello significó su desaparición de la nómina de grandes ganaderos. También el estamento nobiliario se vio afectado por los acontecimientos. Su papel como labradores de sus tierras e, incluso, de otras que tomaban en arrendamiento, al que anteriormente nos hemos referido, cesó a finales del siglo XVIII. Aunque la nobleza no perdió sus tierras durante los procesos desamortizadores, no reemprendió, en general, su actividad labradora, lo que limitó considerablemente su papel como ganaderos.

Todo ello, determinó que hasta mediados del siglo XIX, entre los grandes ganaderos bajoandaluces, se acentuara aún más el papel del arrendatario, ya que a la desaparición, en buena parte, de los grandes ganaderos terratenientes del Antiguo Régimen, el acceso a la propiedad de la tierra de los grandes labradores colonos fue un proceso lento que sólo culminaría durante la segunda mitad del siglo XIX. De los veinticinco grandes ganaderos de los que poseemos descripción de sus bienes durante este período, sólo seis son propietarios de tierras de labor y dehesa, en total unas 4.500 hectáreas, otros cinco poseen sólo haciendas de olivar como bienes rústicos, mientras que los catorce restantes no poseen ningún tipo de tierras y sólo cultivan tierras en condición de colonos. El hecho de que se trate de simples colonos no impidió que estos labradores se hiciesen con grandes extensiones de terreno para su explotación.

35 López MARTíneZ, Antonio Luis: La economía de las órdenes religiosas en el Antiguo Régimen. Sus propiedades y rentas en el reino de Sevilla, Sevilla, 2002. 
Durante la segunda mitad del siglo XIX se generalizaron los procesos de venta que permitieron el acceso de los grandes labradores colonos a la propiedad de la tierra. La finalización de la venta de los bienes eclesiásticos, la venta de los bienes de propiedad municipal con la desamortización civil y la puesta en venta de numerosas propiedades de la nobleza tras la desvinculación de los mayorazgos, significaron la salida al mercado de más de 10.000 .000 hectáreas en toda España. La relación con la tenencia de la tierra de los grandes ganaderos se ha transformado considerablemente, así de los catorce inventarios de bienes correspondientes a este período para la segunda mitad del siglo XIX en nueve casos corresponden a grandes propietarios de tierras que en total suponen más de 13.000 hectáreas propiedad de dichos ganaderos.

El cambio de condición respecto a la tenencia de la tierra de los grandes ganaderos bajoandaluces aparece ilustrado en el caso de Jerez. En el catastro de Ensenada los grandes ganaderos poseen unas 9.000 hectáreas, aunque también hay grandes ganaderos colonos, como muestran algunos inventarios de bienes localizados. La importancia de la terratenencia de los ganaderos se relaciona con la naturaleza de los mismos, entre los que figuran monasterios, como la Cartuja, y varios miembros de la nobleza, como el conde de S. Gil. Las declaraciones juradas de 1819 , muestran una importante reducción de tierras en propiedad en manos de los ganaderos, resultado de la pérdida de condición de ganaderos de los monasterios y algunos títulos nobiliarios. Durante todo el siglo XIX se registra un ascenso de la condición de terratenientes de los grandes ganaderos, de modo que a comienzos del siglo XX, los grandes ganaderos son propietarios del $40 \%$ de las tierras que explotan.

CUADRO 5. EVOLUCIÓN DEL RÉGIMEN DE TENENCIA DE LA TIERRA EN LAS EXPLOTACIONES AGRARIAS DE LOS GANADEROS JEREZANOS (1750-1907)

\begin{tabular}{|l|c|c|c|c|c|c|c|}
\hline & $\begin{array}{c}1750 \\
(24)\end{array}$ & \multicolumn{2}{|c|}{$\begin{array}{c}1819 \\
(13)\end{array}$} & \multicolumn{2}{c|}{$\begin{array}{c}1854 \\
(17)\end{array}$} & \multicolumn{2}{c|}{$\begin{array}{c}1907 \\
(17)\end{array}$} \\
\hline Régimen & Superficie & Superficie & $\%$ & Superficie & $\%$ & Superficie & $\%$ \\
\hline propietario & 8.947 & 2.984 & 26 & 8.912 & 29 & 16.592 & 40 \\
colono & & 8.618 & 74 & 30.997 & 71 & 25.481 & 60 \\
\hline total & & 11.602 & & 39.909 & & 42.073 & \\
\hline
\end{tabular}

los números que figuran entre paréntesis corresponden a los ganaderos incluídos.

Superficie en hectáreas

Fuentes: Catastro de Ensenada, Declaraciones juradas de bienes (Martín de Garay), Amillaramiento y Montañés (1997)

El dato de 1907 es el de las mayores explotaciones agrarias, que han de ser los que, sin duda, tengan la mayor cantidad de ganado.

Todos estos cambios y transformaciones en el régimen de tenencia de la tierra en los grandes ganaderos tuvieron una lógica repercusión en la estructura

Hispania, LXV/3, núm. 221 (2005) 1023-1042 
de sus patrimonios económicos. Hasta 1836, fecha en que comenzaron a ponerse a la venta las propiedades de la Iglesia y de la nobleza, el ganado jugó un papel muy importante en los patrimonios de estos grandes ganaderos, incluso superior al papel representado por las tierras de su propiedad, que al cultivar muchas tierras en régimen de arrendamiento podía ser muy reducido. La adquisición de tierras puestas a la venta con las desamortizaciones por parte de estos grandes labradores-ganaderos hizo que su patrimonio económico aumentase considerablemente y que el valor de sus propiedades territoriales ocupase una considerable proporción en dichos patrimonios.

\section{CUADRo 6. PAPEL DEL GANADO EN LA EVALUACIÓN DE LOS PATRIMONIOS} DE LOS GRANDES GANADEROS ANDALUCES, 1600-1900

\begin{tabular}{|l|c|r|c|c|r|c|}
\hline Período & ganaderos & ganado & $\%$ & \multicolumn{1}{c|}{ tierras } & $\%$ & Patrimonio total \\
\hline $1600-99$ & 16 & 4.834 & 18 & 543 & 2 & 27.200 \\
$1700-99$ & 11 & 193.572 & 16 & 320.504 & 27 & 1.209 .133 \\
$1800-36$ & 9 & 630.065 & 34 & 400.010 & 21 & 1.880 .338 \\
$1837-55$ & 9 & 281.325 & 14 & 851.855 & 43 & 2.001 .195 \\
$1856-99$ & 17 & 689.559 & 11 & 2.739 .143 & 45 & 6.133 .151 \\
\hline
\end{tabular}

datos en reales constantes (base 1790-99)

Valores medio por ganadero

Fuentes: Inventarios notariales de bienes

\section{CONCLUSIÓN}

Al hablar de la agricultura lo que más se ha destacado es la fuerte concentración de la propiedad de la tierra que da lugar al denominado régimen latifundista, sin embargo, tan importante o más fue la concentración que se produjo en la propiedad de la cabaña ganadera. Si bien, la fuerte concentración de la propiedad del ganado no coincidió en todos los casos con la terratenencia. El hecho de que la mayor parte de la las explotaciones se llevasen en régimen de arrendamiento es lo que determina la coincidencia entre los grandes labradores, en gran parte, colonos y los grandes ganaderos que, en general, se trataba de las mismas personas. Esta coincidencia en los intereses agrícolas y ganaderos trajo como consecuencia el intento de acaparamiento de los derechos comunales por parte de los grandes labradores-ganaderos, gracias al control que ejercieron sobre los cargos municipales, dado que era la institución municipal la que, en última instancia, gestionaba el disfrute de tales derechos. De aquí, que el pretendido enfrentamiento secular entre ganaderos y agricultores en Andalucía se tradujese en la pugna entre grandes y pequeños campesinos por el acceso al disfrute de los derechos comunales. 